\title{
Austro-Mistral/Vardarac (Ricardo Aleixo - Delmo Montenegro - Ricardo Corona - Eduardo Jorge - Amador Ribeiro Neto)
}

Luís SERGuilha

Poeta (Portugal)

As estruturações / timbres do teatro/contextura ressaltam no labirinto encantatório da origem do idioma performativo constelações sónicas/ futuráveis articulam os encadeamentos de composição/reorientação dos poetas/pictóricos/arte negra caleidoscópica Delmo Montenegro; Ricardo Aleixo e Ricardo Corona.

A materialidade transmutadora do indizível forma a incomensurabilidade fisiológica dos sentidos/área da estruturação cénica movimentando a coreografia elíptica/orquestradora da dança suprema das palavras “máquina zero"; "corpo sutil"; "ciao cadáver" variações metalinguísticas.

A mobilidade destes signos linguísticos pronuncia as analogias constitutivas da seiva "enteógena" da universalidade cosmológico/autoconsciência dos jogadores de cartas-cinemaginário-roda do mundo, afirmando a absorção da metamorfose da historicidade das artes visuais. Estes cinematógrafos-gráficos-visuais antecipam a transculturalidade como um verdadeiro lugar geometrizante/experiência da língua/cosmos recombinações das afinidades interrogativas sobre(sob) as fainas enfáticas dos desvairamentos poéticos que restituem as percepções/ritualísticas da humanidade permanentemente em desconstrução corpo poema/ silêncio e expressão na palingenesia do mundo.

As transferências das forjas das interpelações/faculdades/ária/dança reaviva os compassos laboriosos do mundo revelador da realização épica/ 
antropológica da vida interior Ricardo Aleixo; Delmo Montenegro e Ricardo Corona circunstancializam o potencial simbólico/sonoro/genesíaco singularizando a multidimensonalidade dos habitates intervenientes do dialecto libertador porque reforçam o transcendentalismo da oralidade e das nomenclaturas melodiosas que mobilizam a substância policromática dos cânticos/alquimia dos gritos-limites (instrumento circulatório da alegoria no interior da singularidade da roda do mundo --cinemaginário --trívio----- ciao cadáver -corpo sutil desconstrução da contemporaneidade da língua entre as macrocircunferências poeticizantes do caos das vozes comunicantes.)

As teias das superfícies arquitectónicas do conflito estético desmesuram as multiplicidades da escrita musical/verbal das explorações excêntricas Aleixianas/Montenegrinas/Coroneanas para plasticizarem a engenharia primordial da anatomia intervisual através dos paralelismos fantasmagóricos/ecos idiomáticos / dispositivos tecnológicos onde a batida da experiência/conhecimento da impossibilidade instaura-se na diversidade etnográfica do principio estrutural do africanismo/tribalismo/translinguístico. Este desejo potencial da transformação está no ritmo da subjectivização orgânica e nos caminhos filosóficos das pirâmides mitológicas, relembrando a fusão dos sentidos das "esculturas povoadas" pelos cantos órficos que sobrelevam a existência/evasão___ (artérias picturais/sonoras)

As hastilhas frásicas percepcionam a dimensão interactiva da intempestiva linguagem da performance citadina/violência/infusão paleontológica coincidindo nas formas sémicas diluídas sobre um número infinito de lugares (mutabilidade das assonâncias das partículas/textuário) ___ _(infinitamente perturbador é o dualismo intraduzibilidade/pluralidade do enigma harmónico/caligráfico/visual entre a informulação dos olhares anarquistas/afloração frásica-experimental/segmentos vibráteis ___ transfusão contínua das consanguinidades rítmicas entre as alternâncias da engrenagem da linguagem que reconhece o espaçamento da concepção/alcançamento musical na fábula cartográfica _ Corona-Delmo- 
Aleixo- "ramificadores" da altercação interna da _coreografia da sílaba, da excepcionalidade da palavra, desenho solar da intertextualidade)

O interceccionismo estético no desdobramento de Delmo Montenegro/Ricardo Aleixo/Ricardo Corona transcendentaliza a linguagem da poesia performativa porque desenha uma nova plurivocalidade representacional da música/linguagem/íngremes raízes de espelhos ao fundar um espírito versátil/latente da criação artística defrontando as multiplicidades dos observadores do tempo, do espaço e da festividade deontológica.

O informulável decurso acústico circunscreve o rendilhado universalista do corpo/poema e as formas contrastantes abalam-se visualmente como energias selvagens do compositor a metaforizarem intrinsecamente as matrizes: som/tom/ritmo originalmente adquiridas a outras visualidades metapoéticas onde o princípio da liberdade absoluta anula o conhecimento teórico procurando a unidade do inexistente e a voz-letra da elementariedade da imaginação.

As finalidades dos detalhes da heterogeneidade elevam o sentido dilacerante da linguagem cinematográfica/composição plástica/sonora para outras expressões relampagueantes nesta estrutura a manifestação dos semiologistas libertários reconhece a ciência do alargamento das emoções _ emoções partilhadas que desafiam/exercitam as interpretações/ autocriações das primitivas afectividades como as luminosidades arquitectónicas a cauterizarem a insustentável cumplicidade rizomática do real/cosmos perspectiva alquímica dos experimentalismos do ecossistema/ espacialização da interdisciplinariedade: estas ligações internas perspectivam a hibridez nativa/geográfica fortemente antropizada pela elementariedade das origens.

Jogadores de cartas; cinemaginário; máquina zero fragmentam os mediadores solares da crosta granítica entre outras autonomias vulcânicas/vertiginosas porque a conversão atmosférica/linguística segue a transposição paleontológica dos sentidos como fundições alegóricas na expansão do fundo oceânico ou (para além das celebridades identitárias/ 
conceptualizações porque o mistério e a volubilidade reinscrevem-se nas interplacas da liberdade dos tremores de terra/poema fulgurante). Aqui no grande corgo das plataformas/infinitudes das interioridades alucinantes a poesia-som (da ancestralidade/afloração electrica avançada) conquista regeneradoramente a dinâmica do alfabeto das cordilheiras.

Geologicamente as alegorias das variações sazonais / abismais da linguagem poética superam a imediatidade entre a obscuridade e o aceso instante do absoluto/musical.

A evocação ritualiza a electricidade da hibridização espaço/tempo/revisitação

do mundo-análogo que empolga a respiração cinética/biológica para reintroduzir a vibração do ciclo caligráfico da água/ciclone de espectros

como um arrebatamento ameríndio a transmutar as substâncias performativas das radiações sobre a investigação abíssica da circulação atmosférica onde a universalidade da génese reconstrói os efeitos mecânicos

dos hieróglifos/ritos/configurações do mundo/ andada primitivista que experimenta a indeterminação do batimento _unidade cinematográfica da instância reinventada pelas fronteiras dos estremecimentos genealógicos da dramatização é nestas imagens cosmogónicas da intertextualidade que a receptividade do elevado limite da cauterização/magnetismo/eclosão aleixiana/montenegrina/coroneana se desencarcera da descrição/representação.

O labirinto hidrológico estende-se metaforicamente na composição florística da interioridade templo/dimensão musical/pluralidade gráfica esta forma do dialogismo biológico personifica a tumultuosa acentuação do centro explosivo voz/realidade do ser/levitação onde a fractura da revelação/alteridade transgride o metabolismo vetegal/poético até à polifonia da atmosfera-outra da rocha-mãe.

Montenegro; Corona; Aleixo _ poetas da impulsão arrebatadora porque possuem a plenitude plástica e sensorial que corporaliza o "pictograma chinês (mu)" que significa "árvore” __ surpreendente enraizamento das 
imagéticas objectualizadas nas configurações ascendentes da reabilitação do eco/pintura_grito onírico conjugados nas iluminações espontâneas das convivências bióticas organismos/expressionistas-vivos na materialização de uma linguagem emergente e insubmissa

renovando os fluxos atmosféricos/marinhos/hipodérmicos para constituir o zonamento poético/musical/cósmico entre o "ideografismo" e a transformação inaugural/criativa/África cenográfica/amplitude gestual

Os ritos espécie emotiva convergem na autenticidade da oscilação subterrânea dos sentidos flexível cerâmica/húmus visionário a descodificar outras efervescências impetuosas para deambular na reinvenção/fabulística da voz das águas pulsionais coroneanas/aleixianas/ montenegrinas ilustradores do cântico topológico/neo-primitivo signo mágico da terra luminosidades dos graffitis depuradores da montanha/cidade/ multidão irreverente grande mural da libertação__. aqui os poetas do austro-Mistral/Vardarac agitam a ascendência imperscrutável do conhecimento/ofício de reencontrar as fantasmagorias/mutações da improvisação/ celular/interrogativa do mundo.

A erosão vertical dos naufrágios/palavras/redescobertas/fermentação da pré-história/pintura sonora totaliza o relevo primitivo pleno de energias cinéticas relevos comparáveis aos monumentos antigos restaurados pelos arqueólogos__(alumiamento incorpóreo)__ contudo a linguagem da gestação intensa dos poemas/onomatopeias desabotoa os materiais geológicos com as superfícies topográficas dos relâmpagos.

Poetas -austro-Mistral-Vardarac- cinzelam a intuição das linhas de fracturas(mutações ininterruptas) procurando outros seres das migrações tróficas/sazonais nas gargantas profundas/electroacústicas onde a microbiologia das crateras meteóricas são centros solares ou eixos imperceptíveis do design gráfico a descerem na impressionabilidade mecânica da turbulência para expandirem/intercepcionarem as variações fonéticas como redes hidrográficas a caracterizarem os utensílios das águas torrenciais.

Neste austro-Mistral/Vardarac quero relembrar Amador Ribeiro 
Neto e Eduardo Jorge Barrocidade e Espaçaria células/rádio das buliçosas altitudes onde a cardinal-deslocação emaranha a geomorfologia do possível mundo originário. O nervo paleontológico da imaginação exalta-se na densidade das contracções tectónicas estremecendo as arestas da descontinuação para recriarem o esplendor da manobra das águas no imo lucífugo da biomassa vegetal. Este cavado diamante da transgressão tropical metamorfose da impossibilidade existencial (sacudidela tectónica na translúcida interrogação das dunas piramidais/aerodinâmicas constituindo a imersão dos microorganismos decompositores/cenográficos da realidade inapreensível)__ magma metapoético a penetrar na incubação infigurável das paisagens oníricas e nas eflorescências das impossibilidades que nos conduzem até à violência afectuosa dos limites.

A ritmicidade gestualista de Amador/expressionista/ Pollockiano converte as originalidades poéticas em abstractos detalhes/signos reintegradores dos relevos vocabulares ou em icebergues árticos/instintuais na alteridade da navegação.

Todo este magnetismo climatológico metamorfoseia os domínios do mosaico vegetal onde os detritos/húmus são mineralizados pelas bactérias da alacridade instantânea.

A vitalidade das matrizes perceptivas e regeneradoras é catapultada pelas proteínas dos mananciais térmicos/vulcânicos biomórficos__é nesta libertação absoluta que se encontra a reserva efervescente e nutritiva dos oceanos bailarinos/poéticos/dilacerantes/deflagração diamantina __ Amador/Eduardo Jorge.

A combinatória de vocábulos participa integralmente no ecossistema da floresta misteriosa e original dos signos impulsivos/ritualísticos de Eduardo Jorge e Amador Ribeiro Neto onde a variedade/esteiras luminosas dos mecanismos da vibrante simbologia desemboca na feracidade da depuração/reinvenção como frentes intertropicais/centrípetas das sensibilidades a dialogarem entre as protuberâncias flamejantes e epistemológicas doutras correntes atmosféricas/visuais / esquadrinhamento cognitivo paisagismo desconceptualizador na felídea garatuja serpenteante da libertação. 
Os elementos imprevisíveis da aliança cristalográfica de Barrocidade e Espaçaria envolvem o prodígio dos elementos nativos no ritmo/miragem/reflexiva destes poetas que penetram nas efabulações e nas habitações estilizadas da petrologia porque as projecções destes poetas representam as revoluções verbais/ascensionais brasileiras como uma espécie de meteorização dança fecunda de entrecruzamentos incontornáveis autonomizando as coordenadas das géneses/perspectivas como um abalo intra/extra/infra celular de germinações infiguráveis e aleatórias a alucinarem as exegeses programáticas e teoréticas.

Austro-Mistral/Vardarac-meridional desnuda a paisagem Poética/ Brasileira

ável da autêntica árvore voadora

para reinaugurar a disseminação permenatureza árvore/macrofotográfica/árvore-organográfica que enceleira a energia das radiações da louca medula da invenção.

Simbologia Nativa

\section{de Adriana Zapparoli}

Adriana Zapparoli universaliza topograficamente a incerteza da particularização do comportamento solar/corporal em consonância com os organismos/signos opticamente suscitados pela impressionabilidade da fascinação.

A dimensão poética de Adriana decanta a irrupção (libertação cosmopolita)___ concupiscência/sensualidade estetizante e exegética ao reconstituir a indomável circunlocução interactiva das desnaturalizações (materialidade extemporânea em expansão nas múltiplas combinações dos espelhos epidérmicos ou nas incandescentes recombinações das engrenagens espontâneas e fisiológicas) desassossego a penetrar nas urdiduras da visão transcendental

Os poemas Zapparolianos revelam a afectividade visual entre a natureza instintiva e as vivificações ascensionais e expansivas da autenticidade dualista_: civilização urbana/origens primitivas-contagiantes.

A alternativa das formas arquétipas e das conceptualizações predeterminadas passa pelas germinações libertadoras e pelas reinaugurações impre- 
visíveis de Adriana Zapparoli unificadora dos ritmos marginais (arquitectura orgânica do vitalismo da metamorfose).

As complexidades dos planos da desnudação da linguagem pigmentam a plenitude dos realizadores da confrontação e as testemunhas (intuições) da linguagem pictórica descodificam os rodopios dinâmicos dos lances corporais como próteses caleidoscópicas a comporem os efeitos performativos dos ecrãs; projecções impulsivas produzindo a exemplaridade da disposição das energias essenciais e imaginativas. Este corpo pulsional e auto-exigente depura as acumulações das narratividades vertiginosamente contíguas à movimentação das alegorias iluminadoras da profundidade

O jogo orquestral das fábulas mistura a constituição/colagem da temporalidade axiomática nas suas formas descentradas (interpelações desartificiosas), como um abalo da pluralidade anatómica a contrastar as interferências da superficialidade orgânica/impremeditada entre as eclosões das estruturas dos interiores do corpo.

A consanguinidade das mitologias é indispensável à vocação imaginária e emancipatóra do turbilhão da representatividade dos signos de Zapparoli, como demonstrações energéticas da corporeidade insubmissa a singularizarem a experiência labiríntica da condição terrestre

(intersecções de espelhos objectualizadas nas manifestações excitatórias/metafísicas das performances zoológicas _ o Leão de Neméia animais apócrifos a regenerarem a experiência da infinitude da luminosidade/palavra fundição dos círculos arqueológicos e visionários .)

As montagens dos vórtices da ancestralidade/evolucionismo fisicalizamse nas coordenadas astrais dos poemas onde as tonalidades da problematização faunística levitam entre o transvasamento das celebrações antiarquetípicas e a redescoberta da vocação instintivamente sensorial.

A resistência da eroticidade balanceia a imprevisibilidade escultórica da transmutação orgânica e selvagem; fenomenologia do biologismo poético a deambular na marginalidade da auto-realização ou no confessiona- 
lismo Zapparoliano unificador da imperscrutabilidade felina

A bidimensionalidade reinventa-se e consubstancia-se nas dissecações policromáticas do descobrimento turbulento porque recupera

as cadências sensórias-motoras-multiformes e subleva-se na pulsionalidade do deslumbramento da consciência criadora

porque recusa o absolutismo científico e o asfixiante encontro das formulações do convencionalismo.

Zapparoli homenageia a unidade instintual da visão cósmica emancipando a motricidade nativa das cenografias barrocas e a praticabilidade das hemorragias combinatórias

do despenhadeiro / espiralado/plasticizante/caleidoscópico;

como um élan de sustentáculos expansivos a abrilhantarem

a interiorização das perspectivas do corpo/vida/expressividade/ somatização dos exílios originalidade do grito afectivo agilidade da inscrição neoprimitiva ___ correnteza e embate cósmico.

A variabilidade mobilizadora das especificidade enérgicas colide nas circularidades dos desnudamentos para estilizarem o próprio movimento das explosões coreográficas, assim Adriana Zapparoli transforma a procriação do invisível

sobre a instabilidade física do corpo/linguagem inexplorada/ visualizações assombrosas da subjectividade, combinando os organismos dos pensamentos emancipatórios noutros corpos-astrais-astrais-corpos/ ritmicidade intersubjectiva das exposições do mundo animal.

Este quadro de assentamentos orientalizantes e de independências globais permite a espontaneidade íntima e fascinante do relâmpago corporal

para desconvencionalizar a objectividade diurnal e a presença normativa.

O potencial dos utensílios libertadores de Adriana prolifera na criatividade do nervo eléctrico da explicação do absurdo como um povoamento de fusões inconformáveis a condensar o arrebatamento excêntrico da armadilha libidinal e a destotalizar a contemporização do determinismo biológi- 
$\mathrm{CO}$ (segredo-pintura-escrita-da-

dissemelhança mutação identificadora das voltagens da heterogeneidade)

As proeminências da actividade imaginária fracturam as patologias da geometrização mundana, elevando a focalidade infinita da autonomia para subverter a des-subjectivação da cidade/corpo através do delírio imagístico do desregramento. As vibrações do conflito/corpo/Zapparoli/historicidade__ geóloga/reinvenção da liberdade respiratória descondiciona a actividade imaginária; integrando a cristalização da sensorialidade ancestral entre as intercomunicações da visibilidade mitológica e a percepção dos arquipélagos da receptividade totalizadora de o Leão de Neméia e Leonella.

\section{Cristalografias do subsolo (Sol sobre Nuvens)}

Deixa-me em paz.com as tuas paisagens! Fala-me do subsolo.

Samuel Beckett

Josely Vianna Baptista corpo-claridade esfíngica_ar das labaredas a reactualizar a profundidade da comunicação radical apresentada pela forja das correspondências dos espelhos sobre a imparcialidade do ser-desconhecido da transmudação fulgente (busca da submersão do mistério da realidade intraduzível)

Josely reinaugura simultaneamente o estonteamento da universalidade hiante e os filamentos relampagueantes dos atlas botânicos como a densidade cósmica e sonambúlica a atravessar as coordenadas da combustão (sísmica e bifurcada _ _ inacessibilidade distanciadora/particularização da substância interior)

Estes signos-electrochoques penetram na estabilidade do vocabulário dos climas luminíferos para magnetizarem a dissecação geomorfológica da linguagem (absoluta) através do corpo da metamorfose femínea eclodindo fulgurantemente na invenção das desvairadas disposições das simbioses.

As fabulações do metabolismo linguístico Joselyniano propiciam a anti-instrumentalização da consciência afectiva 
na alucinação sensorial dos nascimentos insulanos, transgredindo a discursiva antiguidade doutra efabulação reinventada na translucidez da periodicidade selvagem onde as vulnerabilidades dos obstáculos da conceptualidade equiponderam/recriam a violenta atracção da origem inexplicável

Corpografias analógicas no esquematismo-mistral doutro corpo possível e investigável (gravura de ar torrencial) noutro corpo da libertação instantânea e hiperbólica poeta/mineralogista a reabilitar a indeterminação das identidades externas/intrínsecas fortemente potencializadas pelo físico/linguístico indefinível que reproduz o supremo paroxismo do desejo ao diferenciar a materialização da preciosidade indecifrável.

Convulsivamente o desejo-corpo-razão-emoção-abaladura reencontra/ improvisa a energia alucinatória das caligrafias-signos até à revelação do dinamismo silencioso das vigilâncias topológicas, teatralizadas pelas equações escultóricas do auto-conhecimento.

Ar (disseminação da nebulosidade solar) sobre a instauração metamórfica do infigurável onde as arqueologias regeneradoras do corpo/perspectiva substancializam os símbolos delirantes das corporalidades contíguas porque a espessidão das fronteiras da catástrofe elementar alastrase na actividade complexa da anti-teorização do desornamento visual onde a superposição dos interstícios descentralizadores reintegram as acepções exímias dos ricochetes epistemológicos da ruptura eruptiva dos confins órficos

Ar-segredo turbulento a aventurar-se na reunião das fragmentações das vivências cósmicas tornando peregrinas as práticas das representações selváticas/paradoxos febris contra a amofinação da imediatidade dos corpos.

A composição da heterogeneidade dos mistérios iniciáticos projecta os novos primitivismos inventivos; os novos tribalismos da advocatura erecta do silêncio bandos porosos e germinativos rasgando as especificidades da endoculturação; reimplantando a ascendência do encontro do desejo-corpo entre a mutabilidade/mobilidade das pulsões autocriativas como plantas vasculares a fecundarem a região alegórica dos inconscientes 
Josely/corpos de vulcanologias intransferíveis a abalançarem as consistências da desconstrução/construção de ecossistemas sobre as formulações expressivas das interioridades corpos na multidão dissolvida pela frangibilidade do deserto/ corpo construtor espelho a espelho/ janela a janela magnificamente mar febril/órgão sob(sobre) proliferações mutantes

As ambivalências das representações multicelulares/transimagéticas reincorporam as divulgações das performances/experiência da descoberta transmissora das consciências interpoladas entre a significabilidade das defrontações reprodutivas e as cisões da carnalidade (naufrágio sobre as metamorfizações semânticas monumento simultaneamente híbrido e interrogativo )

Corpografias na substância nutritiva do Ar (Sol que não regressa sobre as nuvens___profundeza poética

Poros flóridos/mutação da cifra do corpóreo onde a continuada insinuação das caligrafias oscilatórias desequilibra o manancial das incoincidências dilacerantes das sismologias florísticas. Alavancas das conflitualidades das vivificações contra a neutralização das sínteses do descobrimento geológico___ esta eloquência das ressonâncias imagéticas é deslumbrante porque permanece na descentralização fenomenológica do corpo/ texto/motricidade amorosa da plasticização.

Josely desfigura a estilização das harpas das imagens ao desencadear as sinalizações voláteis do corpo/incógnita. $\mathbf{O}$ espargimento lexical aferrolha a imersão (impulso motor) doutro corpo ambígeno (descendência do abismo caracterizando o mandamento da mecânica geneticista/orgánica/textual como uma catedral cinematográfica dos reflexos e das fendas graníticas ou será a pré-história do apocalipse na materialidade da investigação do inexprimível sobre o corpo-da-matriz-microbiológica que explode a sua germinação na receptividade idiomática das fundições paroxísticas.

A dimensão perceptiva condensa-se nas deambulações do corpo/muralista ou nos espelhamentos agrupados noutros chamamentos inorgânicos (luminosamente a cachoeira das atmosferas barrocas procura a visibilidade incisiva da unidade histórica para participar na totalização do desconhecido 
como uma azagaia vibratória da singularidade afectiva a penetrar nas gramalheiras do ostracismo da linguagem Realização/transformação do ser fulguroso alcance do écran regenerador das físicas corporais diferenciando a área da irredutibilidade do movimento de outros territórios mensageiros das informuláveis linguagens (linguagens das fibras inenarráveis sobre o violento arremesso da dualidade_: mecanização das formulações das loucas realidades / sentidos tempestuosos no desmancho das encruzilhadas botânicas.

A porosidade heterogénea da contemporaneidade é indeterminada sobre as avenidas extravasantes dos sentidos como as intempéries epidérmicas a transcenderem as matrizes das perspectivas entre a sublimidade da defrontação perceptiva. Aqui Josely interroga a reconstituição das contrariedades pulmonares da referencialidade-: fotometrias/flora/planetologia através dos desenhos-ou infravermelhos das geometrizações das inflorescências); identificando as vocações dos rituais neo-primitivos (difusamente metalizados pela libertação mais interior/ difusamente transmutados na espontaneidade vegetativa

As ultrapassagens insituáveis das dessemelhanças da civilização mais insondável (des)centraliza a existência bravia como a determinação da especiosidade botânica a articular a universalidade das desconceptualizações das Corpografias___Ar___Poros Flóridos cristalografias a desocultarem as biografias-figurações do subsolo

Os excertos da elementaridade corporal bruxuleiam até aos confins inomináveis da intelecção da afectividade/espécie livre textura dos epítomes alucinatórios da percepção

A plenitude dos poemas impulsiona figurativamente a impressão rítmica do rejuvenescimento da lubricidade como a rebentação dos domínios da celebridade/lava a cadenciar os elementos inspirados das efígies eixos fundadores do esplendor dos simulacros composição das morfologias dos axiomas excepcionais onde a dinâmica iniciadora do enquadramento florístico é percepcionada na geneticização da alteridade humana/ terrestre reconciliação do mapeamento da singularidade das transgressões entre as micro assimetrias dos palimpsestos que constituem a densidade iniciadora dos corpos/vegetais incicatrizáveis 
A somatologia das circunscrições fantasmagóricas interposiciona-se nas focalizações constitutivas do mestiçamento dos signos suspensos noutro corpo universalmente antropológico e a vivacidade primordial da cisão excêntrica do corpo/poema representa a incontaminada amplitude da metamorfose meteórica matéria-prima indefinidamente manipulável sobre(intra) os cosmos balbuciantes contidos nos genomas universalizáveis das alternâncias rítmicas ___Reservatório da desordem/ ordem das figuras-signos onde as biografias das afinidades descobrem a poesia das possibilidades plásticas entre a dramaticidade da amplitude rizomática Josely/hieroglífica duma visibilidade que autonomamente engendra a intensificação do limite libertador poética dos líquenes da essência amplificando as expressividades coruscantes, enigmáticas sobre os signos da circularidade semiológica Esta incorporação orgânica esta mutação vertiginosa do principio medular dissemina as telas das fulgurações como um movimento de escamas genesíacas a ritualizarem a tremulação da substância do indecifrável

Sol sobre Nuvens especificidade (im)penetrável do Teatroaberto onde os espaços ancestrais/contemporâneos reorganizam a potencialidade das descrições da odisseia poética instante vertiginosamente teatralizado na transitividade das reminiscências do louco organismo.

\section{Referências Bibliográficas}

ALEIXO, Ricardo. Roda do mundo. Belo Horizonte: Objecto Livro, 2004. - Trivio. Belo Horizonte: Scriptum, 2004. . Máquina zero. Belo Horizonte: Scriptum, 2001.

BAPTISTA, Josely Vianna. Sol sobre nuvens. São Paulo: Perspectiva, 2006.

CORONA, Ricardo. Cinemaginário. São Paulo: Iluminuras, 2006. Corpo sutil. São Paulo: Iluminuras, 2005.

JORGE, Eduardo. Espaçaria. São Paulo: Lumme, 2007.

MONTENEGRO, Delmo. Ciao cadáver. São Paulo: Landy, 2005. - Jogadores de cartas. Recife: Bagaço, 2003.

RIBEIRO NETO, Amador. Barrocidade. São Paulo: Landy, 2003. ZAPPAROLI, Adriana. Neméia. Et Cetera, Curitiba, n. 6, set. 2005. 